Working

Paper

Department

of Economics

$\mathrm{Ca}^{\prime}$ Foscari University of

Venice

Valentina Bosetti

Carlo Carraro

Marzio Galeotti

The dynamics of carbon and energy intensity in a model of endogenous technical change 


\title{
The dynamics of carbon and energy intensity in a model of endogenous technical change
}

\author{
Valentina Bosetti \\ Fondazione Eni Enrico Mattei \\ Carlo Carraro \\ University of Venice, Fondazione Eni Enrico Mattei, CEPR, CESifo and CEPS
}

\author{
Marzio Galeotti \\ Fondazione Eni Enrico Mattei
}

\begin{abstract}
In recent years, a large number of papers have explored different attempts to endogenise technical change in climate models. This recent literature has emphasized that four factors - two inputs and two outputs - should play a major role when modelling technical change in climate models. The two inputs are R\&D investments and Learning by Doing, the two outputs are energy-saving and fuel switching. Indeed, R\&D investments and Learning by Doing are the main drivers of a climatefriendly technical change that eventually affect both energy intensity and fuel-mix. In this paper, we present and discuss an extension of the FEEM-RICE model in which these four factors are explicitly accounted for. In our new specification of endogenous technical change, an index of energy technical change depends on both Learning by Researching and Learning by Doing. This index enters the equations defining energy intensity (i.e. the amount of carbon energy required to produce one unit of output) and carbon intensity (i.e. the level of carbonization of primarily used fuels). This new specification is embodied in the RICE 99 integrated assessment climate model and then used to generate a baseline scenario and to analyze the relationship between climate policy and technical change. Sensitivity analysis is performed on different key parameters of the energy module in order to obtain crucial insights into the relative importance of the main channels through which technological changes affects the impact of human activities on climate.
\end{abstract}

\section{Keywords}

Climate Policy, Environmental Modelling, Integrated Assessment, Technical Change

JEL Codes

$\mathrm{H} 0, \mathrm{H} 2, \mathrm{H} 3$

Address for correspondence:

Carlo Carraro

Department of Economics

Ca' Foscari University of Venice Cannaregio 873, Fondamenta S.Giobbe 30121 Venezia - Italy Phone: (++39) 0412349166 Fax: (++39) 0412349176

e-mail: ccarraro@unive.it

This Working Paper (o QD se in inglese) is published under the auspices of the Department of Economics of the Ca' Foscari University of Venice. Opinions expressed herein are those of the authors and not those of the Department. The Working Paper series (o QD se in inglese) is designed to divulge preliminary or incomplete work, circulated to favour discussion and comments. Citation of this paper should consider its provisional character

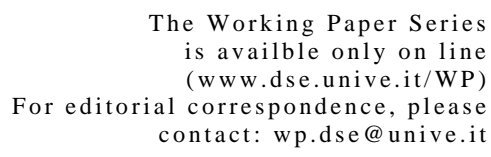

is availble only on line

contact:wp.dse@unive.it
Department of Economics
Ca' Foscari University of Venice
Cannaregio 873, Fondamenta San Giobbe
30121 Venice Italy
Fax: + + 39412349210 


\section{Introduction}

Controlling the influence of human activities on climate is not an easy task. The international agreement reached in Kyoto that has so far come into force will have a very small impact on greenhouse gas (GHG) atmospheric concentrations. Stabilizing these concentrations at, for example, twice the pre-industrial levels requires per capita global emissions to peak and then decline to (at least) half their 1990 value by the end of the twenty-first century (Cf. Bosetti, Galeotti, and Lanza, 2004). This seems to be feasible only through drastic technological change in the energy sector, leading to the substitution of obsolete and dirty technologies with cleaner ones. There are therefore no substitutes for policy in directing innovation efforts toward fostering economic growth and helping the environment at the same time.

All the above remarks are reflected in climate models, the main quantitative tools designed either to depict long-run energy and pollution scenarios or to assist in climate change policy analysis. Indeed, these models have traditionally accounted for the presence of technical change, albeit usually evolving in an exogenous fashion. More recently, however, models have been proposed where technology changes endogenously and/or its change is induced by deliberate choices of agents and government intervention. Both bottom-up and top-down models - a long standing distinction in energy-economy-environment modelling - have been recently modified in order to accommodate forms of endogenous technical change. As it turns out, the bottom-up approach has mostly experimented with the notion of Learning by Doing, while a few top-down models have entertained the notion of a stock of knowledge which accumulates over time via R\&D spending. ${ }^{1}$

The purpose of this paper is to present and test a new climate model which accounts for various features of technical change. In the new model, dubbed FEEM-RICE v.3, changes in technology affect the economy and climate through modifications of both the energy intensity of production and 
the carbon emission intensity of energy consumed. The driver of these intensity ratios is a new variable, deemed Energy Technical Change Index (ETCI), which is a convex combination of two stocks, an abatement-based one and an R\&D-based one. These stocks are designed to capture the two main modes of endogenous technical change, Learning-by-Doing $(L b D)$ and Learning-by-Researching $(L b R)$.

Crucial technical change parameters are calibrated in order to obtain a baseline which reproduces the SRES B2 emission scenario (as in Boyer and Nordhaus, 2000) with technical change having both an exogenous and an endogenous component. When stabilization scenarios are simulated, an induced technical change part gets added to those two components. In order to better understand the model structure, we also carry out a number of optimisation runs in which key technical change parameters are modified and their impact on energy and carbon intensity are quantified. This sensitivity analysis enables us to test the robustness of the model and to identify the main parameters driving our main results.

The remainder of the paper is as follows. Section 2 presents the FEEM-RICE v.3 model and provides a short technical description of how technical change has been modelled. Section 3 describes the baseline calibration process. Section 4 presents our main results and the conclusions arising from our sensitivity analysis. In section 5, some policy remarks and suggestions for further research close the paper.

\section{Modelling Induced Technical Change: The FEEM-RICE v.3 Model}

The FEEM-RICE v.3 model is an extended version of the RICE 99 model by Boyer and Nordhaus (2000). ${ }^{2}$ RICE 99 is a Ramsey-Koopmans single sector optimal growth model suitably extended to incorporate the interactions between economic activities and climate. There is one such model for each of the eight macro regions into which the world is divided:

\footnotetext{
${ }^{1}$ A review of the recent literature on the role of technical change in the economics of climate change and on the incorporation of induced technical change in climate-economy models can be found in Carraro and Galeotti (2002, 2004); Clarke and Weyant (2002); Löschel (2002).

${ }^{2}$ RICE 99 is an extension of the RICE 96 model described in Nordhaus and Yang (1996).
} 
USA, Other High Income countries (OHI), OECD Europe (Europe), Russia and Eastern European countries (REE), Middle Income countries (MI), Lower Middle Income countries (LMI), China (CHN), and Low Income countries (LI).

Within each region a central planner chooses the optimal paths of two control variables, fixed investment and carbon energy input, so as to maximize welfare, defined as the present value of per capita consumption. The value added created via production (net of climate change) according to a constant returns technology is used for investment and consumption, after subtraction of energy spending. The technology is Cobb-Douglas and combines inputs from capital, labour and carbon energy together with the level of technology. In RICE 99, population (taken to be equal to full employment) and technology levels grow over time in an exogenous fashion, whereas capital accumulation is governed by the optimal rate of investment.

The production function of the original RICE 99 model is ( $n$ indexes regions, $t$ time periods):

$$
Q(n, t)=A(n, t)\left[K_{F}(n, t)^{1-\gamma-\alpha_{n}} C E(n, t)^{\alpha_{n}} L(n, t)^{\gamma}\right]-p_{n}^{E} C E(n, t)
$$

where $Q$ is output (gross of climate change effects), $A$ the exogenously given level of technology and $K_{F}, C E$ and $L$ are the inputs from physical capital, carbon energy and labour, respectively, and $p^{E}$ is fossil fuel price. Carbon emissions are proportional to carbon energy, that is:

$E(n, t)=\zeta(n, t) C E(n, t)$,

where $E$ is industrial $\mathrm{CO}_{2}$ emissions, while $\varsigma$ is an idiosyncratic carbon intensity ratio which also exogenously declines over time. In this way, Boyer and Nordhaus (2000) make the assumption of a gradual, costless improvement of the green technology gained by the agents as time goes by. 
This treatment of technical change appears inadequate for a model designed to study issues related to climate change.

In this paper we present and apply a new model in which technical change is endogenous and responds to climate policy as well as to other economic and policy incentives. Therefore, both endogenous and induced technical change effects will be taken into account. In FEEM-RICE v.3, we consider simultaneously both $L b D$ and $L b R$ as inputs of endogenous and induced technical change and we focus on the effects of technical change on both the energy intensity of production and the carbon intensity of energy use. These features of the model allow us to address both energy-saving and energy-switching issues. To clarify this aspect it is perhaps useful to refer to a time-honoured concept in environmental economics, namely the Kaya's identity, which in the present specific case reads as follows:

$$
E(t)=\sum_{n}\left(\frac{E(n, t)}{C E(n, t)}\right)\left(\frac{C E(n, t)}{Q(n, t)}\right)\left(\frac{Q(n, t)}{L(n, t)}\right) L(n, t),
$$

where $E$ is world emissions, $C E$ is carbon energy, and $L$ is population. Hence, world emissions are a product of two 'forces': techno-economic forces, given by carbon intensity $(E / C E)$ and energy intensity $(C E / Y)$, and socio-economic forces, given by per capita output $(Y / L)$, as well as demographic dynamics $L$. In addition to socio-economic forces - income and population - which are commonly modelled in endogenous growth models, our model allows us to endogenise both techno-economic forces, namely energy and carbon intensity.

The main novelty of our new formulation hinges on the relationship between technical change and both Learning-by-Researching and Learningby-Doing at the same time. We assume that energy-saving and climatefriendly innovation is brought about by $R \& D$ spending which contributes to the accumulation of the stock of existing knowledge. ${ }^{3}$ In addition to this

\footnotetext{
${ }^{3}$ Therefore, the focus is on energy-related R\&D. It has to be pointed out that analysing $R \& D$ expenditure is complicated because (i) R\&D is not always amenable to measurement and (ii) there is a great deal of uncertainty
} 
Learning-by-Researching effect, the model also accounts for the effect of Learning-by-Doing, now modelled in terms of cumulated abatement efforts. Thus, our index of technical change, ETCI (Energy Technical Change Index), is defined as a convex combination of the stocks of knowledge and abatement:

$\operatorname{ETCI}(n, t)=K_{R}(n, t)^{c} \operatorname{ABAT}_{s}(n, t)^{d}$,

where $K_{R}(n, t)$ is the stock of knowledge and $A B A T_{s}$ represents the stock of cumulated abatement, in turn defined as:

$A B A T_{S}(n, t+1)=\delta_{A} A B A T_{F}(n, t)+\left(1-\delta_{B}\right) A B A T_{s}(n, t)$.

$A B A T_{F}$ the abatement flow, $\delta_{\mathrm{A}}$ the learning factor, i.e. the amount of abatement which translates into a learning experience, and $\delta_{\mathrm{B}}$ being the depreciation rate of cumulated experience. The stock of knowledge $K_{R}(n, t)$ accumulates in the usual fashion:

$K_{R}(n, t+1)=R \& D(n, t)+\left(1-\delta_{R}\right) K_{R}(n, t)$,

where $\delta_{\mathrm{R}}$ is the depreciation rate of knowledge. Without loss of generality we assume that $d=(1-c)$.

How does our index of energy technical change affect the rest of the economy? The variable ETCI is assumed to affect both energy intensity (i.e., the quantity of energy required to produce one unit of output) and carbon intensity (i.e., the level of carbonization of primarily used fuels). As seen in equation (1), the factors of production are labour, physical capital and carbon energy. Let us first consider the effect of technical progress on factor productivity (the energy-intensity effect). In our model, the production function (1) is replaced by the following equation:

in the ability of R\&D to generate technological change. These words of caution should be therefore borne in mind by the reader when going through the paper. 
$Q(n, t)=A(n, t)\left[K_{F}(n, t)^{1-\alpha_{n}(E T C l)-\gamma} C E(n, t)^{\alpha_{n}(E T C I)} L(n, t)^{\gamma}\right]-p_{e}(n, t) C E(n, t)$,

where:

$\alpha_{n}=\alpha_{n}[\operatorname{ETCI}(n, t)]=\frac{\vartheta_{n}}{2-\exp \left[-\beta_{n} \operatorname{ETCI}(n, t)\right]}$,

and $\theta_{n}$ and $\beta_{n}$ are region specific parameters, calibrated to have -in the base year- $\alpha_{n}$ exactly as in the original formulation of the production function. Thus, an increase in the endogenously determined ETCI reduces - ceteris paribus - the output elasticity of the energy input. It is worth noting that in (1') $A(n, t)$, the Hick's neutral component of technological progress, accounts for a fraction of technical change which evolves exogenously, thus following an explicit suggestion by Clarke and Weyant (2002).

Let us now turn to the effect of energy technical change on the carbon intensity of energy consumption. As shown in (2), effective energy results from both fossil fuel use and (exogenous) technical change in the energy sector. In our model, we assume that ETCI serves the purpose of reducing, ceteris paribus, the level of carbon emissions. More precisely, equation (2) is replaced by:

$E(n, t)=h[C E(n, t), E T C(n, t)]=\varsigma(n, t)\left\{\frac{1}{2-\exp \left[\psi_{n} \operatorname{ETCI}(n, t)\right]}\right\} C E(n, t)$.

Again, parameters in equation (2') have been calibrated in order to replicate the base year in the original formulation. Here an increase in ETCI progressively reduces the amount of emissions generated by a unit of fossil fuel consumed. Finally, we recognize that $R \& D$ spending absorbs some resources, that is:

$Y(n, t)=C(n, t)+I(n, t)+R \& D(n, t)$, 
where $Y$ is output net of climate change effects, $C$ is consumption, $I$ is gross fixed capital formation and $R \& D$ is research and development expenditures. In order to account for the difference between private and public return to investments in R\&D, we follow Popp (2004) and model the positive externality of knowledge creation by assuming that the return on $R \& D$ investment is four times higher than the one in physical capital. At the same time, the opportunity cost of crowding out other forms of $R \& D$ is obtained by subtracting four dollars of private investment from the physical capital stock for each dollar of $R \& D$ crowded out by energy $R \& D$, so that the net capital stock for final good production becomes:

$$
K(n, t+1)=K(n, t)(1-\delta)+(I(n, t)-4 * \lambda * R \& D(n, t)),
$$

where $\lambda$, the crowding out parameter, represents the percentage of other R\&D crowded out by energy R\&D.

The optimal dynamic path of all variables of the model is determined by solving an intertemporal optimisation problem. Control variables (physical investments, R\&D investments and energy demand) are computed within a game-theory framework. Each country plays a non-cooperative Nash game in a dynamic setting which yields an Open Loop Nash equilibrium.

\section{Calibration of the Baseline}

To further clarify our formulation of endogenous and induced technical change, let us highlight the dynamic interrelationships between the different variables and their role in the model. First of all, let us notice that R\&D is a control variable, whereas stock of knowledge and cumulated abatement are state variables. Therefore, R\&D can be used strategically by regulators in each region of the model, whereas $L b D$ is an output of the regulator's strategic behaviour. This is quite clear at the beginning of the game (see Figure 1). At stage one, only $L b R$ through R\&D investments occurs. This 
modifies our index of energy technical change ETCI and yields some amount of abatement, i.e. some abatement experience which becomes $L b D$. Both $L b R$ and $L b D$ then affect ETCI in the subsequent stages.

In short, the fundamental driver of technical progress is $R \& D$ investment. This induces knowledge accumulation and experience in emission abatement in various regions of the world. In turn, these variables move technology towards a more environment-friendly dynamic path.

Our quite general solution to account for endogenous and induced technical change comes obviously at a cost. Basically, little information to calibrate the model parameters is available. The best strategy we can follow is to calibrate parameters in order to replicate, in the baseline, emissions of the SRES B2 scenario (IPCC, 2000), which are also the baseline emissions in the original RICE 99 model by Boyer and Nordhaus (2000).

Given the high degree of freedom characterizing the calibration process, there exist many distinct baseline models representing different interpretations of what role the exogenous and endogenous components should play in the baseline.

We emphasize this fact by using two versions of the FEEM-RICE v.3, called FAST and SLOW FEEM-RICE. The two versions primarily differ in the value of the learning factor, $\delta_{\mathrm{A}}$, defined as the rate at which accumulation of past abatement becomes effective experience. Therefore, it represents the effectiveness of Learning by Doing. In particular the FAST version of the model assumes a $10 \%$ learning factor as opposed to the $5 \%$ learning factor of the SLOW version. In addition to this, the two versions of the model differ in the magnitude of the crowding out effect of investment in energy R\&D on other research investments, which in turn controls for the profitability of $R \& D$ investments. Differences in these two key features imply a substantially different contribution of the exogenous component the declining trend in carbon intensity ratio, described by $\varsigma(n, t)$ in equation (2')- versus the endogenous component of technical change in the baseline (see Table 3). A comparison of the two versions - also with respect to the original RICE 99 model and with respect to FEEM-RICE without 
endogenous technical change - is shown in Tables 1 and 2. In particular, the percentage change cumulated in year 2105 with respect to base year 1995, both of the energy intensity and of the carbon intensity ratios are presented.

Figure 1. The Structure of Technical Change in FEEM RICE v.3

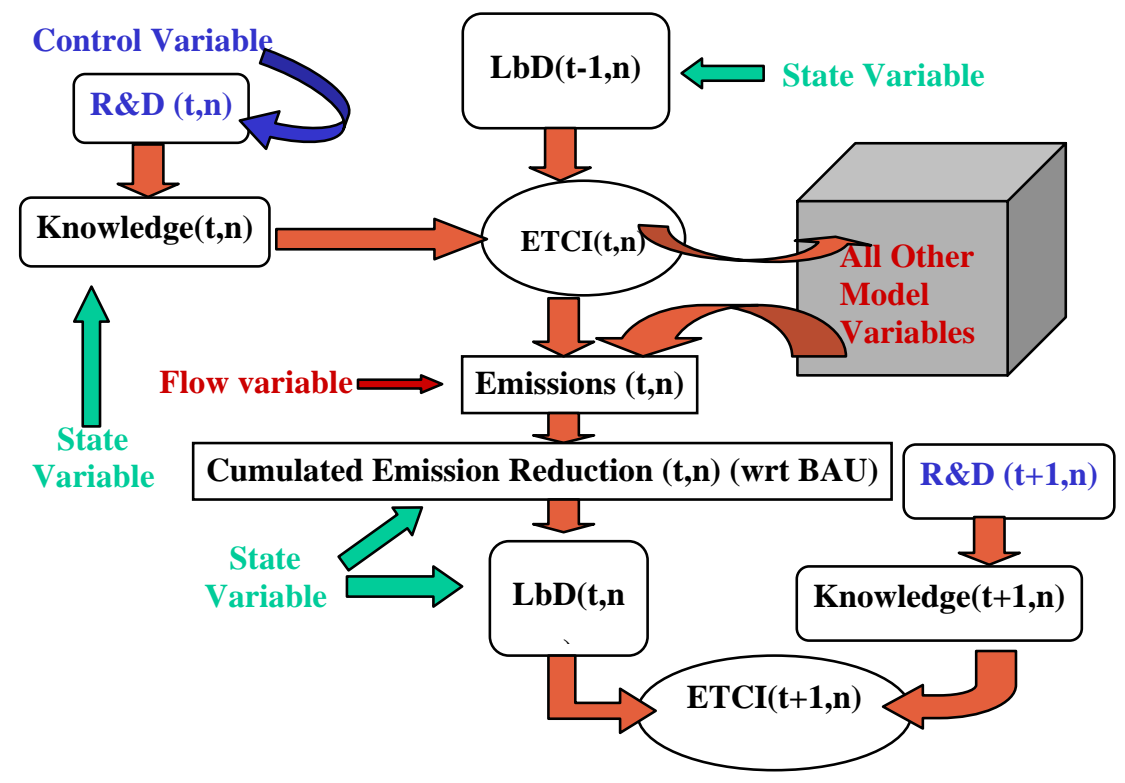

Notice that, in the original RICE 99 model, technical change was not only exogenous, but was also assumed to display its effects almost exclusively on carbon intensity. By contrast, in our new model, both carbon intensity and energy intensity are modified by the presence of an index of energy technical change, which is endogenous and depends on both $R \& D$ investments and Learning by Doing effects. The balance between the effect on carbon intensity and the one on energy intensity depends on the parameters $\beta$ and $\psi$ that have been calibrated to reproduce Boyer and Nordhaus (2000)'s baseline scenario. A careful sensitivity analysis on these two coefficients has been performed. Results are reported below.

In addition, the endogenous component is larger in the FAST version of FEEM RICE v.3 than in the SLOW version (see Table 3). The reason is the enhanced effectiveness of energy technical change in the FAST version, 
where energy $R \& D$ crowds out a smaller amount of other types of $R \& D$ and where $\mathrm{LbD}$ is faster.

Table 1. Contributions of Different Technical Change Components to Lowering Carbon and Energy Intensity in the FAST Version of FEEM-RICE v.3: 1995-2105 Cumulated Effects.

\begin{tabular}{|c|c|c|c|c|}
\hline Baseline & Fordhaus & $\begin{array}{c}\text { v.3 } \\
\text { with }\end{array}$ & $\begin{array}{c}\text { FEST } \\
\text { RICEM- }\end{array}$ & $\begin{array}{c}\text { FEEM-RICE } \\
\text { Rith only } \\
\text { wiCE } \\
\text { Learning by } \\
\text { Researching* }\end{array}$ \\
\hline $\begin{array}{c}\text { Carbon Energy/Production } \\
\text { Carbon Emissions/Carbon }\end{array}$ & $-2.74 \%$ & $-10.59 \%$ & $-26.92 \%$ & $-10.79 \%$ \\
\hline Energy & $-66.52 \%$ & $-40.77 \%$ & $-66.14 \%$ & $-49.01 \%$ \\
\hline
\end{tabular}

Table 2. Contributions of Different Technical Change Components to Lowering Carbon and Energy Intensity in the SLOW version of FEEM-RICE v.3: 1995-2105 Cumulated Effects.

\begin{tabular}{|c|c|c|c|c|}
\hline Baseline & $\begin{array}{c}\text { Nordhaus } \\
\text { RICE 99 }\end{array}$ & $\begin{array}{c}\text { FEEM-RICE } \\
\text { v.3 with } \\
\text { Exogenous TC }\end{array}$ & $\begin{array}{c}\text { SLOW } \\
\text { FEEM- } \\
\text { RICE } \\
\text { v.3 }\end{array}$ & $\begin{array}{c}\text { FEEM-RICE } \\
\text { with only } \\
\text { Learning by } \\
\text { Researching* }\end{array}$ \\
\hline $\begin{array}{c}\text { Carbon Energy/Production } \\
\text { Earbon Emissions/Carbon } \\
\text { Energy }\end{array}$ & $-2.74 \%$ & $-6.83 \%$ & $-13.76 \%$ & $-7.13 \%$ \\
\hline
\end{tabular}

* The scenario in which we consider only Learning by Researching without any consequent Learning by Doing effect must be considered as a benchmark case in which we set to zero the coefficient relating the amount of cumulated abatement to the dynamics of our index of energy technical change. 
Table 3. Exogenous and Endogenous Share of Total Energy Technical Change Measured as the Effect on the Carbon Intensity Index in the Baseline Scenario (1995-2105).

\begin{tabular}{|l|c|c|}
\hline \multicolumn{1}{|c|}{ Baseline } & Exogenous TC & Endogenous TC \\
\hline FAST FEEM-RICE v.3 & $62 \%$ & $38 \%$ \\
\hline SLOW FEEM-RICE v.3 & $87 \%$ & $13 \%$ \\
\hline
\end{tabular}

Finally, notice that the effects shown in Table 1-3 refer to the baseline scenario without any stabilisation target and/or climate policy. More relevant effects on and of technical change will be shown in the next section where the control variables will be optimised to achieve a stabilisation target and to maximise welfare. In this new context, more technical change will become optimal (namely more R\&D investments). Therefore, the endogenous component of energy technical change will be integrated by an induced component (which therefore reduces the share of the exogenous component. See Table 4 below). The FEEM-RICE v.3 model enables us to disentangle the three components of technical change and to quantify the induced (additional) R\&D investments in new energy technologies that it would be optimal to carry out in order to achieve a given stabilisation target.

\section{Induced Energy Technical Change and the Cost of GHG Stabilisation}

The model briefly described in the previous two sections has been used to analyse the economic implications of stabilising emissions at three different target levels: 450,500 and $550 \mathrm{ppm}$ in $2100 .^{4}$ In this section we present only some of the results that we obtained, with the objective of clarifying the properties of the model more than providing an exhaustive economic and environmental analysis of our optimisation runs. Therefore, we will limit our analysis to the SLOW version of the model, which is less optimistic with respect to the future evolution of technical change.

${ }^{4}$ Let us underline that the model is not a multi gas model and therefore accounts for $\mathrm{CO} 2$ emissions only. 
When simulating a scenario with an imposed constraint on carbon concentrations, there will be some additional effort to be undertaken by the central planner of each region in order to limit their share of emissions. We refer to the associated additional technical change as induced technical change.

Table 4. Exogenous, Endogenous and Induced Share of Total Energy Technical Change Measured as the Effect on the Carbon Intensity Index in the Three Stabilisation Scenarios (19952105). SLOW Version of FEEM-RICE v.3.

\begin{tabular}{|l|c|c|c|}
\hline \multicolumn{1}{|c|}{ SLOW FEEM-RICE } & $\begin{array}{c}\text { Exogenous } \\
\text { TC }\end{array}$ & Endogenous TC & Induced TC \\
\hline $\mathbf{4 5 0}$ ppm scenario & $74.8 \%$ & $11.4 \%$ & $13.8 \%$ \\
\hline $\mathbf{5 0 0}$ ppm scenario & $75.9 \%$ & $11.6 \%$ & $12.5 \%$ \\
\hline $\mathbf{5 5 0}$ ppm scenario & $79.4 \%$ & $12.1 \%$ & $8.5 \%$ \\
\hline
\end{tabular}

First of all, let us assess how technical change reacts to the introduction to more stringent policy objective. From Table 4 and from Figure 2, it is clear that more ambitious targets imply an increasing investment in energy $R \& D$ and a greater incidence on the endogenous and induced components of energy technical change. In particular, the share of induced technical change becomes $13.8 \%$ in the $450 \mathrm{ppm}$ scenario, whereas the endogenous component (including the induced one) doubles with respect to the one in the baseline scenario. In addition, as visible in Figure 2, not only a more stringent constraint on the stabilization level implies increasing cumulated investment in energy $R \& D$, but also the distribution over time of these investments is extremely influenced. While in the case of a $450 \mathrm{ppmv}$ stabilization target a dramatic and immediate increase in investment in energy R\&D would be required, in the other two cases this effect would be procrastinated to later periods (2025). 
Table 5. Endogenous and Induced Share of Total Energy Technical Change Index. Percentage Variation between 1995 and 2105 - SLOW Version of FEEM-RICE v.3.

\begin{tabular}{|l|c|c|}
\hline \multicolumn{1}{|c|}{ SLOW FEEM-RICE } & Endogenous TC & Induced TC \\
\hline 450 ppm scenario & $24 \%$ & $76 \%$ \\
\hline 500 ppm scenario & $29 \%$ & $71 \%$ \\
\hline 550 ppm scenario & $37 \%$ & $63 \%$ \\
\hline
\end{tabular}

Our index of energy technical change ETCI strongly increases as a reaction to the stabilisation target. ETCI reaches a peak after the mid of next century as a consequence of the large $R \& D$ investments that countries find it optimal to carry out from 2020 to 2050 . Even though the model takes into account crowding effects in $R \& D$ investments and even though the focus is only on energy $R \& D$ and the related knowledge accumulation, the path of technical change which is necessary to stabilise GHG concentrations at 450 ppm seems unlikely to be realistic. Also notice that between $2 / 3$ and $3 / 4$ of the change in ETCI is induced by the imposition of a stabilisation target (see Table 5). This again shows that $R \& D$ investments three of four times larger than those in the baseline would be necessary to achieve a stabilisation target. $^{5}$

If we look at costs, the impact of stabilisation targets does not seem to be high, at least as far as cost are measured by GDP losses (see, for example, Figure 3 for the more ambitious and costly target). There are two reasons. First, in the model GDP losses are lowered by the positive effects of stabilisation on the environment (in our model lower concentrations imply lower GDP losses). Second, losses in terms of consumption are compensated by an increase of investments, in particular investments in R\&D.

\footnotetext{
${ }^{5}$ In this paper we use a macro model of the world economy in which there is only one type of energy R\&D investment. Therefore, it is not possible to identify which technologies/sectors R\&D investments should focus on, or have been channeled to, to achieve a reduction in carbon and energy intensities.
} 
Figure 2. The Dynamics of ETCI in the Three Stabilisation Sscenarios. SLOW Verison of FEEM RICE v.3.

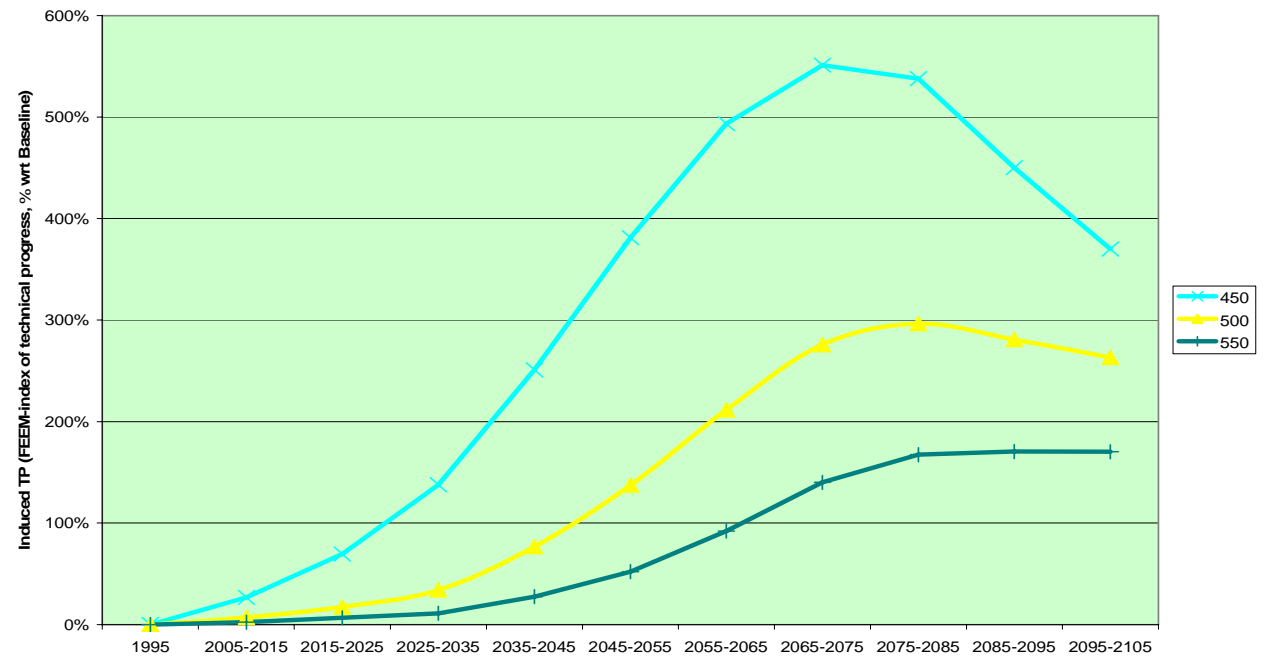

Figure 3. The GDP Cost of Stabilising GHG Concentrations at $450 \mathrm{ppm}$ With and Without Induced Technical Change (1990 USD in MER).

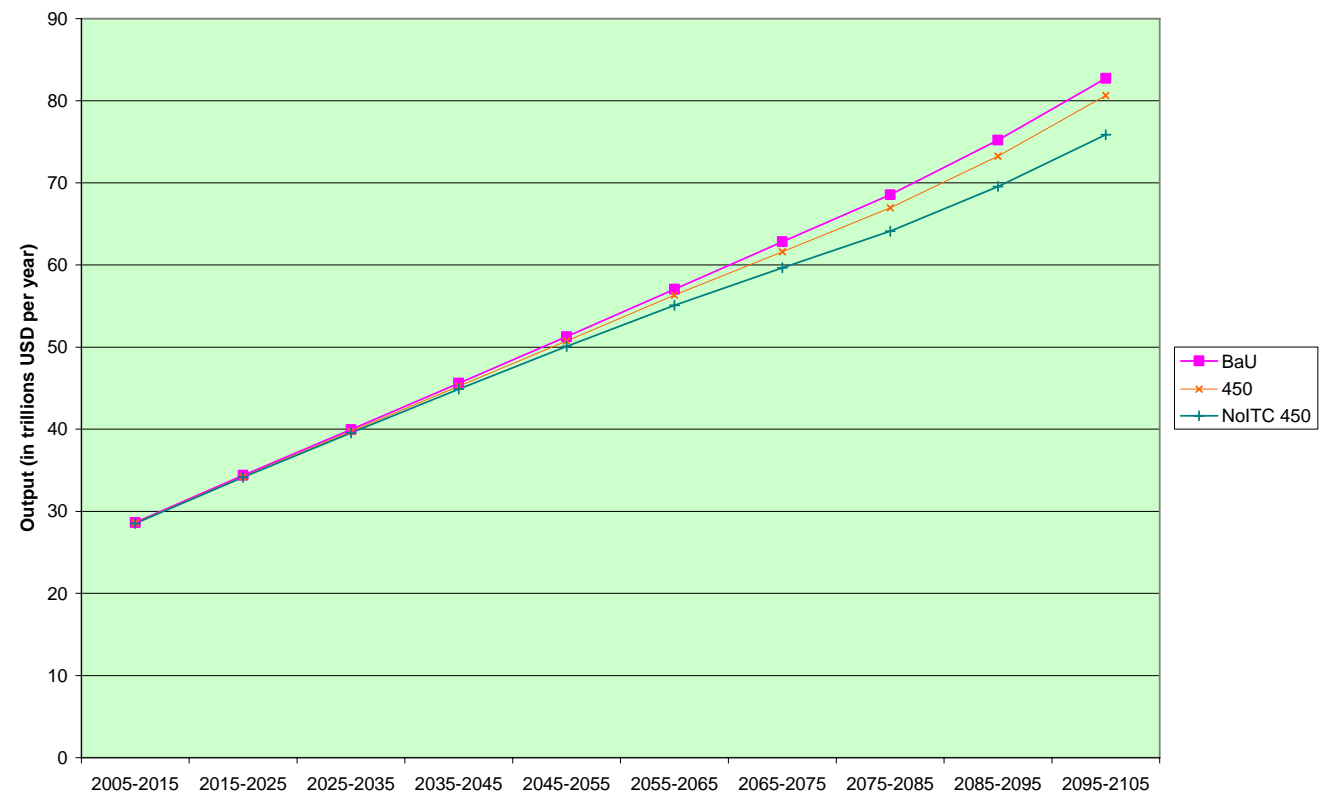

Similar conclusions can be shown if costs are measured in terms of welfare losses (see Figure 4). 
Figure 4. Welfare Cost of Stabilising GHG Concentrations With and Without Induced Technical Change. SLOW Version of FEEM RICE v.3.

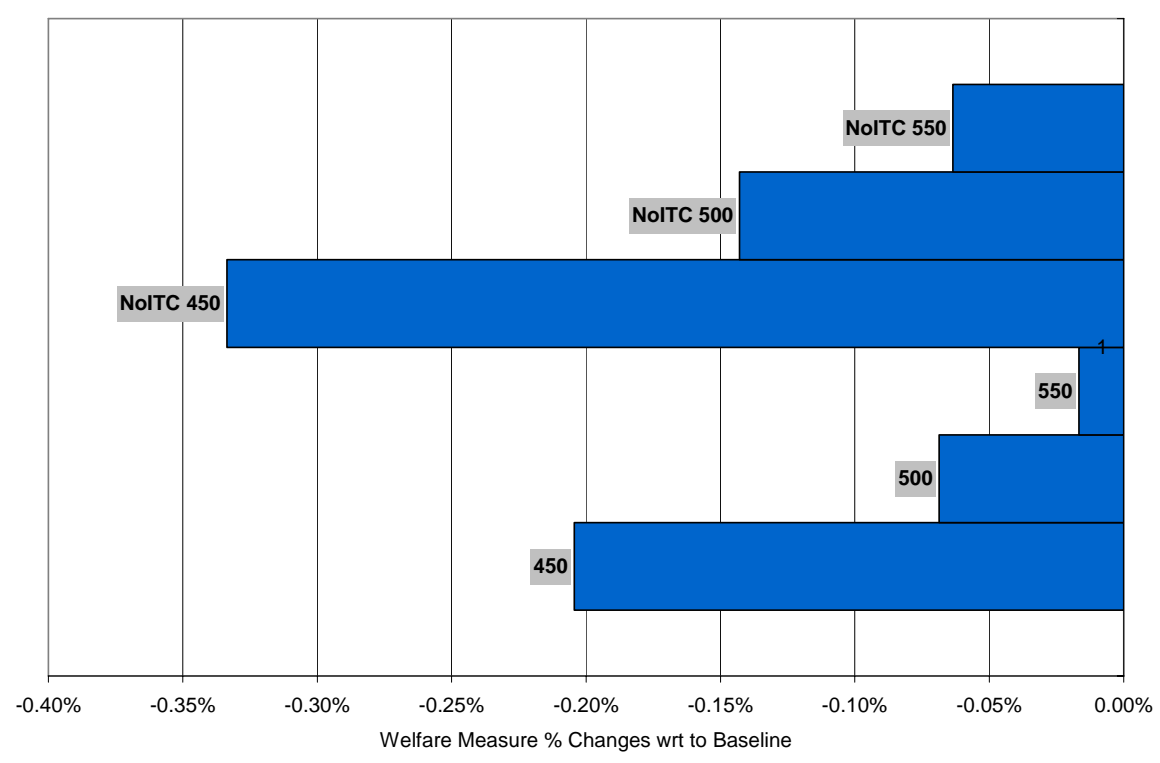

Finally, given the uncertainty on some crucial parameters of the model, we carried out an extensive sensitivity analysis that helped us to check the robustness of the model and of the conclusions that can be derived by using our model. Again, we cannot show all results. We focus therefore on the main parameters that define our specification of endogenous technical change. In particular, through the parameter $c$ we control for the role of researching vs. learning in the process of technical change, whereas through the parameters $\beta$ and $\psi$ we control for the impact of technical progress on energy intensity and carbon intensity respectively. Again we show results only for the SLOW version of FEEM RICE v.3. The initial values of the main parameters are shown in Table 6 below. 
Table 6. Initial Parameter Values for the Technical Change Module of the Model

\begin{tabular}{|c|c|c|c|c|c|c|c|}
\hline Parameter & $\beta(\mathrm{n})$ & $\psi(\mathrm{n})$ & $\mathrm{c}$ & $\delta_{\mathrm{P}}$ & $\delta_{\mathrm{A}}$ & $\delta_{\mathrm{B}}$ & $\mathrm{d}$ \\
\hline Value & $(0.1-0.2)$ & $(0.9-1.2)$ & 0.5 & 0.05 & 0.05 & 0.05 & $1-\mathrm{c}$ \\
\hline
\end{tabular}

Extensive sensitivity analysis has been performed on the parameters $\beta, \psi$ and $c$. Results are shown in Tables 7-9.

Table 7. Sensitivity with respect to Energy-Saving Effect Controlling Parameter. Percentage Change Relative to the Central Value Case.

\begin{tabular}{|l|r|r|r|r|}
\hline & $-\mathbf{0 . 0 5}$ & $\begin{array}{r}\text { centra } \\
\mathbf{I} \text { value }\end{array}$ & $\mathbf{+ 0 . 0 5}$ & $+\mathbf{0 . 1}$ \\
\hline $\begin{array}{l}\text { Atmospheric concentration of carbon (GTC) in } \\
\mathbf{2 1 0 0}\end{array}$ & $1.29 \%$ & - & $-1.30 \%$ & $-3.18 \%$ \\
\hline Atmospheric temperature (deg C) in $\mathbf{2 1 0 0}$ & $0.94 \%$ & - & $-1.13 \%$ & $-2.78 \%$ \\
\hline $\begin{array}{l}\text { R\&D Expenditure as \% of GDP (1990 USD in } \\
\text { MER). }\end{array}$ & $6.75 \%$ & - & 45.22 & 116.05 \\
\end{tabular}

Table 8. Sensitivity wit respect to Fuel-Switching Effect Controlling Parameter. Percentage Change Relative to the Central Value Case.

\begin{tabular}{|l|r|r|r|r|r|}
\hline & $-\mathbf{0 . 4}$ & $-\mathbf{0 . 2}$ & $\begin{array}{r}\text { central } \\
\text { value }\end{array}$ & $+\mathbf{0 . 2}$ & $+\mathbf{0 . 4}$ \\
\hline $\begin{array}{l}\text { Atmospheric concentration of carbon } \\
\text { (GTC) in } \mathbf{2 1 0 0}\end{array}$ & $2.69 \%$ & $1.29 \%$ & - & $1.16 \%$ & $-2.21 \%$ \\
\hline Atmospheric temperature (deg C) in $\mathbf{2 1 0 0}$ & $1.86 \%$ & $0.94 \%$ & - & $0.92 \%$ & $-1.81 \%$ \\
\hline $\begin{array}{l}\text { R\&D Expenditure as \% of GDP (1990 } \\
\text { USD in MER). }\end{array}$ & $-15.58 \%$ & $6.75 \%$ & - & $5.18 \%$ & $9.15 \%$ \\
\hline
\end{tabular}


Table 9. Sensitivity wit respect to Different ETCI Formulations. Percentage Change Relative to the Central Value Case.

\begin{tabular}{|l|r|r|r|r|r|}
\hline & $\mathbf{c}=\mathbf{0 . 0}$ & $\mathbf{C}=\mathbf{0 . 2 5}$ & $\begin{array}{c}\text { central } \\
\text { value }\end{array}$ & $\mathbf{c}=\mathbf{0 . 7 5}$ & $\mathbf{c}=\mathbf{1 . 0 0}$ \\
\hline $\begin{array}{l}\text { Atmospheric concentration of } \\
\text { carbon (GTC) in 2100 }\end{array}$ & $-2.52 \%$ & $-0.90 \%$ & - & $1.27 \%$ & $0.27 \%$ \\
\hline $\begin{array}{l}\text { Atmospheric temperature (deg C) } \\
\text { in } \mathbf{2 1 0 0}\end{array}$ & $-2.25 \%$ & $-1.05 \%$ & - & $1.00 \%$ & $-0.29 \%$ \\
\hline $\begin{array}{l}\text { R\&D Expenditure as \% of GPD } \\
\mathbf{( 1 9 9 0} \text { USD in MER). }\end{array}$ & $-99.77 \%$ & $57.39 \%$ & - & $61.66 \%$ & $316.60 \%$ \\
\hline
\end{tabular}

The most important conclusion is the high sensitivity of $R \& D$ expenditure with respect to the coefficients $\beta$, ..c. The less effective is technical change in reducing GHG emissions the higher the increase in energy-related R\&D expenditure which is necessary to stabilise GHG concentrations.

\section{Concluding Remarks}

In the model presented in this paper, both Learning by Researching and Learning by Doing are explicitly accounted for through an index of energy technical change. Moreover, our index of Technical Progress affects both the relationship between the variables of the macro-dynamic model and energy intensity and the one with carbon intensity. R\&D investments induce the developments of environment-friendly technologies through which GHG emission abatement can be undertaken. At the same time, these abatement activities increase experience and produce learning, which enhance the effectiveness of environment-friendly technologies in reducing GHG emissions. The emission reduction takes place through both energy-saving and fuel-switching effects. In the model, the different components of technical change have a differentiated impact on both effects.

The model has been used to assess the economic costs of achieving different stabilisation targets. Our results suggest that these costs can be 
small, if adequate R\&D investments can be financed and undertaken. Therefore, models in which technical change is exogenous and/or stabilisation targets induce no change in the optimal trajectory of energyrelated innovation are likely to over-estimate the actual stabilisation costs.

An extensive sensitivity analysis with respect to the main parameters of our $2 \times 2$ formulation of technical change has been carried out. This sensitivity analysis has shown the robustness of the model when parameters are changed around the calibrated values and the consistency of the results when large changes in the parameters are imposed.

The next steps in our research agenda can be described as follows. It would be useful to extend the model in order to include a non-energy sector, thus making it possible to have a better representation of fuel-switching dynamics. Second, the possibility of a growing effectiveness of carbon sequestration technologies could be accounted for in the model. Finally, and most importantly, stochastic components of the process of technical change - and therefore uncertainty - must be modelled to develop a more realistic analysis of climate policy.

\section{References}

Bosetti, V., M. Galeotti, and A. Lanza (2004). "How Consistent are Alternative Short-Term Climate Policies with Long-Term Goals?" Fondazione Eni Enrico Mattei, Working paper N.157.2004.

Boyer, J. and W.D. Nordhaus (2000). Warming the World. Cambridge: MIT Press.

Carraro, C. and M. Galeotti (2002). "Traditional Environmental Instruments, Kyoto Mechanisms and the Role of Technical Change." in Carlo Carraro and Christian Egenhofer, eds., Firms, Governments and Climate Policy Incentive-based Policies for Long-term Climate Change, Cheltenham: Edward Elgar. 222-66.

Carraro, C. and M. Galeotti (2004). "Does Endogenous Technical Change Make a Difference in Climate Change Policy Analysis? A Robustness 
Exercise with the FEEM-RICE Model." Fondazione Eni Enrico Mattei, Working Paper N.152.04.

Clarke, L.E. and J.P. Weyant (2002). "Modeling Induced Technological Change." in A. Grübler, N. Nakicenovic and W.D. Nordhaus, eds., Technological Change and the Environment. Washington D.C.: Resources for the Future. 320-63.

IPCC (2000). Special Report on Emissions Scenarios, Nakicenovic N. and R. Swart, eds., Cambridge U.K.: Cambridge University Press. 612.

Löschel, A. (2002). "Technological Change in Economic Models of Environmental

Policy: A Survey.” Ecological Economies 43, 105-126.

Nordhaus, W.D. and Z. Yang (1996). "A Regional Dynamic GeneralEquilibrium Model of Alternative Climate-Change Strategies." American Economic Review 4, 741-765.

Popp, D. (2004). "ENTICE: Endogenous Technological Change in the DICE Model of Global Warming." Journal of Environmental Economics and Management 48, 742-768. 